\title{
Concrete reinforced with various amounts of steel fibers reclaimed from end-of-life tires
}

\author{
Matgorzata Pająk ${ }^{1, *}$ \\ ${ }^{1}$ Silesian University of Technology, Faculty of Civil Engineering, Department of Structural Engineering, Gliwice, Poland
}

\begin{abstract}
The main objective of the paper was to provide more information about the influence of fibers coming from the end-of-life tires on the behaviour of concrete. Because of their untypical geometrical characteristic they are not eagerly applied as concrete reinforcement. Considering the amount of used tires, the management of this waste would be beneficial for the environment. The paper deals with the typical floor concrete reinforced with three dosages of fibers equal to: $30 \mathrm{~kg} / \mathrm{m}^{3}, 40 \mathrm{~kg} / \mathrm{m}^{3}$ and $60 \mathrm{~kg} / \mathrm{m}^{3}$. The compressive and flexural mechanical parameters of RSFC were studied. The waste fibers with the shape dissimilar to manufactured fibers did not have a negative effect on the properties of the mix in a fresh state. The compressive strength was slightly affected by the fibers, meanwhile the pronounced influence of RSF on the post-peak flexural parameters was noted. Those parameters increased proportionally with the amount of fibers. However, the scatters in the flexural tests results were increasing with the fibers content. The investigations indicate that the fibers from the end-of-life tires could be applied as a concrete reinforcement. The values of flexural parameters which can be further applied to structural calculations were shown.
\end{abstract}

\section{Introduction}

In recent years, the end-of-life tires became an important environmental issue. The recycling of tires has increased because Europe and US have forbidden land filling and stock piling of them. Considering a huge amount of endof-life tires used every year, the tires began to be one of the most recycled products. One of the components obtained in the recycled process next to rubber particles is a steel cord. The possibility of application of rubber particles in concrete in order to improve acoustic and thermal isolation has been proved by some researchers. The rubber decreases the mechanical parameters of concrete, hence, as a result that kind of concrete can be used only in non-structural applications, like building facades. The second component formed during the recycling of tires - the steel cord - can be used as concrete reinforcement [1-7]. Despite the fact that many scientists have proven the effectiveness of waste fiber in improving of the parameters of concrete [6,7,9-15], it is still not popularly applied because of its geometrical characteristic.

The main function of randomly distributed reinforcement is to control the crack opening and propagation in the matrix. It is well known that the addition of fibers improves the ductility, strain at peak load, energy absorption capacity but also tensile and flexural mechanical parameters [16,17]. The fibers enhance also the properties of concrete under dynamic loading, mainly considering the damage control [18].

The effectiveness of fibers in the concrete matrix depends on their amount, distribution and orientation.
However, the geometrical parameters of fibers determine their efficiency the most $[19,20]$. The fiber of one length can attract only limited range of concrete strain. The shorter fibers delay the formation and propagation of the micro-crack which increases the hardening phase. The longer fibers are responsible for improving the strength and ductility of concrete due to bridging the macrocracks that develop in concrete [16].

From that case, the idea of mixing various types of fibers that would attract the cracks at different levels was proposed [21]. The hybrid mixes which consist of fibers of different types has found many enthusiasts among scientists [22,23]. They have demonstrated the advantages that are coming from inclusion of hybrid reinforcement.

In case of recycled steel fibers (RSF) their dimensions are directly connected with the process of their reclamation from the tires. The length of the fibers varies in a range of $1 \div 70 \mathrm{~mm}$ based on analysis of the length distribution presented in $[6,9,11,14,15]$. Considering aforementioned, the RSF are a mix of fibers of different lengths, hence can be treated as hybrid mix, which are more effective it enhancing the parameters of concrete [22]. The small diameter of fibers assures higher fibers slenderness than any other manufactured fibers. The length to diameter ratio can reach the value of even 300 [11]. This is well known that with the increase of slenderness of fibers their effectiveness in the concrete matrix increases.

Further, the curved and twist longitudinal shape of RSF should also be treated as an advantage. The problem connected with the influence of fibers orientation on the

Corresponding author: malgorzata.pajak@polsl.pl 
mechanical parameters of concrete is minimalized. That kind of fibers are distributed in the concrete mix in nondirectional manner, additionally not related to the direction of concreting. Considering their small diameter, the amount of fibers in a given volume content is much higher than in the case of typical fibers with a larger diameter. A larger amount of fibers give a more homogeneous mix, what is desired for concrete from any point of view.

However, these advantages over typical fibers can be insufficient in an aggressive environment. In that case mainly the fiber diameter determines the durability of fiber. However, it should be remembered that the fibers are generally not recommended for use in aggressive environmental conditions.

Considering all above the author's aim was to investigate the real influence of waste fibers of untypical geometry on flexural parameters of concrete. The typical floor concrete was used as a matrix for three amounts of recycled steel fibers. The mechanical parameters that can be used in calculation of typical structural elements were presented.

\section{Experimental program}

\subsection{Materials and mix composition}

The typical floor concrete, which detailed composition was presented in Table 1, was used as a matrix. The cement CEM III $42.5 \mathrm{~N}$, locally available sand and coarse aggregate were applied. To achieve proper workability of the mix in the fresh state the Glenium SKY 592 superplasticizer was used in the amount of $0.5 \%$ of the mass of cement.

The fibers which were possessed from the end-of-life tires (RSF) were used as concrete reinforcement. The length of the fibers was in a range of $2 \div 30 \mathrm{~mm}$. Among the fibers few pollutions and bigger fibers could be found, which was shown in the Fig. 1. The total amount of gum particles according to the producer, which are impossible to avoid considering the reclamation process, did not exceed $2 \%$ by volume. The RSF were added to concrete with the amount equal to $0.38 \%, 0.51 \%, 0.76 \%$ which is the dosage weight of $30 \mathrm{~kg} / \mathrm{m}^{3}, 40 \mathrm{~kg} / \mathrm{m}^{3}$ and $60 \mathrm{~kg} / \mathrm{m}^{3}$, respectively. The fibers content was chosen to cover the range of practical application of manufactured fibers. The mix without fibers was also tested for the purpose of comparison.

Table 1. Mixture composition of RSFC.

\begin{tabular}{|c|c|}
\hline Cement CEM III $42.5 \mathrm{~N}\left[\mathrm{~kg} / \mathrm{m}^{3}\right]$ & 350 \\
\hline Natural sand $(0-2 \mathrm{~mm})\left[\mathrm{kg} / \mathrm{m}^{3}\right]$ & 660 \\
\hline Coarse aggregate $(2-16 \mathrm{~mm})\left[\mathrm{kg} / \mathrm{m}^{3}\right]$ & 1175 \\
\hline Superplasticizer $\left[\mathrm{kg} / \mathrm{m}^{3}\right]$ & 1.75 \\
\hline Water $\left[\mathrm{kg} / \mathrm{m}^{3}\right]$ & 165 \\
\hline Steel fibres $(\%)$ by volume & $0.38 ; 0.51 ; 0.76$ \\
\hline $\mathrm{w} / \mathrm{c}$ & 0.47 \\
\hline
\end{tabular}

The specimens were cast in iron moulds in wet conditions for $24 \mathrm{~h}$ after concreting. After that time they were demoulded and placed in a curing room at humidity
$95 \% \mathrm{RH}$ and the temperature $20^{\circ} \mathrm{C}$ until the time of testing. Mechanical properties in compression and flexure were tested on 28-day concrete specimens. Five specimens were tested for each mix.

The results from the investigation of the concrete presented in this paper and other type of concrete reinforced with the amount of RSF equal to $0.38 \%$ was previously presented in [24].

Table 2. Properties of fibers from the end-of-life tires (RSF)

\begin{tabular}{|c|c|}
\hline Length [mm] & $2 \div 30$ \\
\hline Diameter [mm] & $0.15 \pm 5 \%$ \\
\hline Tensile strength [MPa] & $\geq 2850$ \\
\hline $\begin{array}{c}\text { Aspect ratio } \\
\text { (length/diameter) }\end{array}$ & $13 \div 200$ \\
\hline Longitudinal shape & irregular (curved, twisted) \\
\hline
\end{tabular}

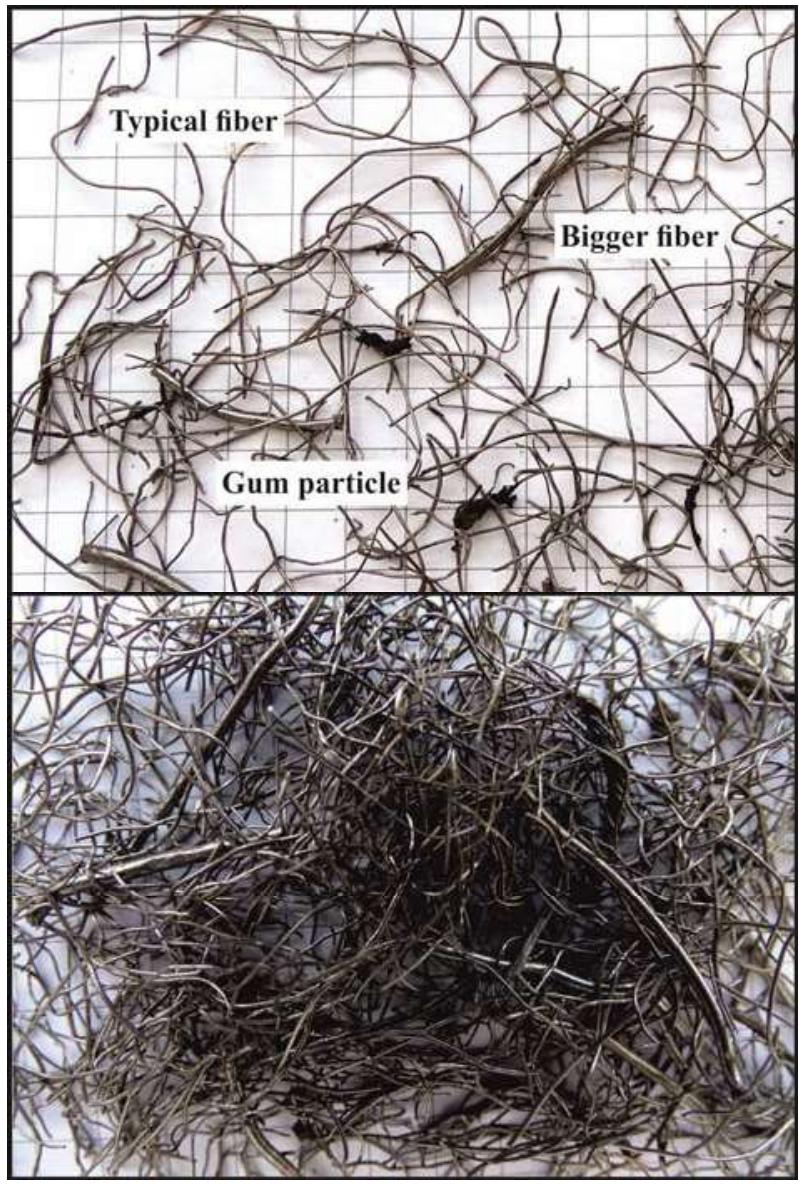

Fig. 1. Fibers from end-of-life tires.

\subsection{Test procedures}

The laboratory experiments were performed at the Faculty of Civil Engineering of the Silesian University of Technology.

The compressive strength of RSFC was determined on the cylinders with the dimension of $150 \times 300 \mathrm{~mm}$ according to PN-EN 12390-3 [25]. The compressive tests were carried out in $3000 \mathrm{kN}$ hydraulic compression testing machine with the constant rate of loading.

The three-point flexural tensile tests were performed according to RILEM TC 162-TDF [26] on the notched 
beams with the dimension of $150 \times 150 \times 600 \mathrm{~mm}^{3}$ (Fig. 2). All the tests were performed in the servo-hydraulic testing machine MATEST $(\mathrm{C} 109 \mathrm{~N})$ with the rate of midspan deflection equal to $0.2 \mathrm{~mm} / \mathrm{min}$. The crack mouth opening displacement (CMOD) was measured simultaneously with the beam deflection with the clip gage attached at the knife-edge. The deflections were measured simultaneously by using two linear variable displacement transducers (LVDT) (Fig. 3).

The tests were performed until the beam reached the deflection corresponding to $1 / 150$ of the span, thus equal to $5 \mathrm{~mm}$.

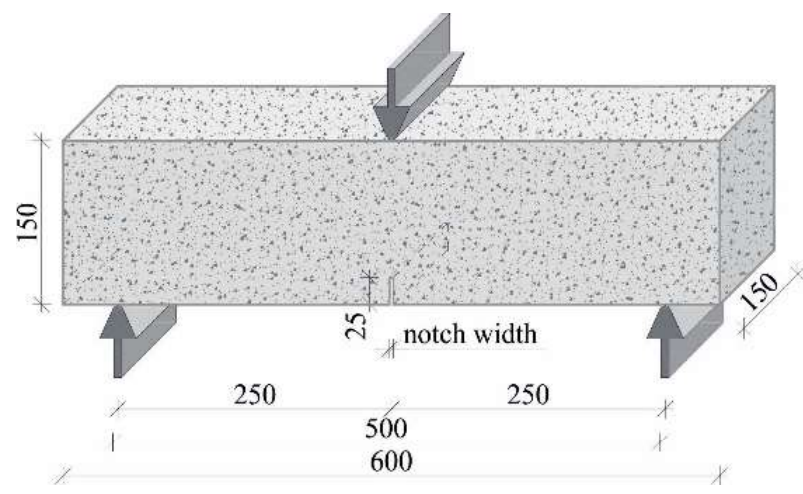

Fig. 2. Specimens dimension and test setup.
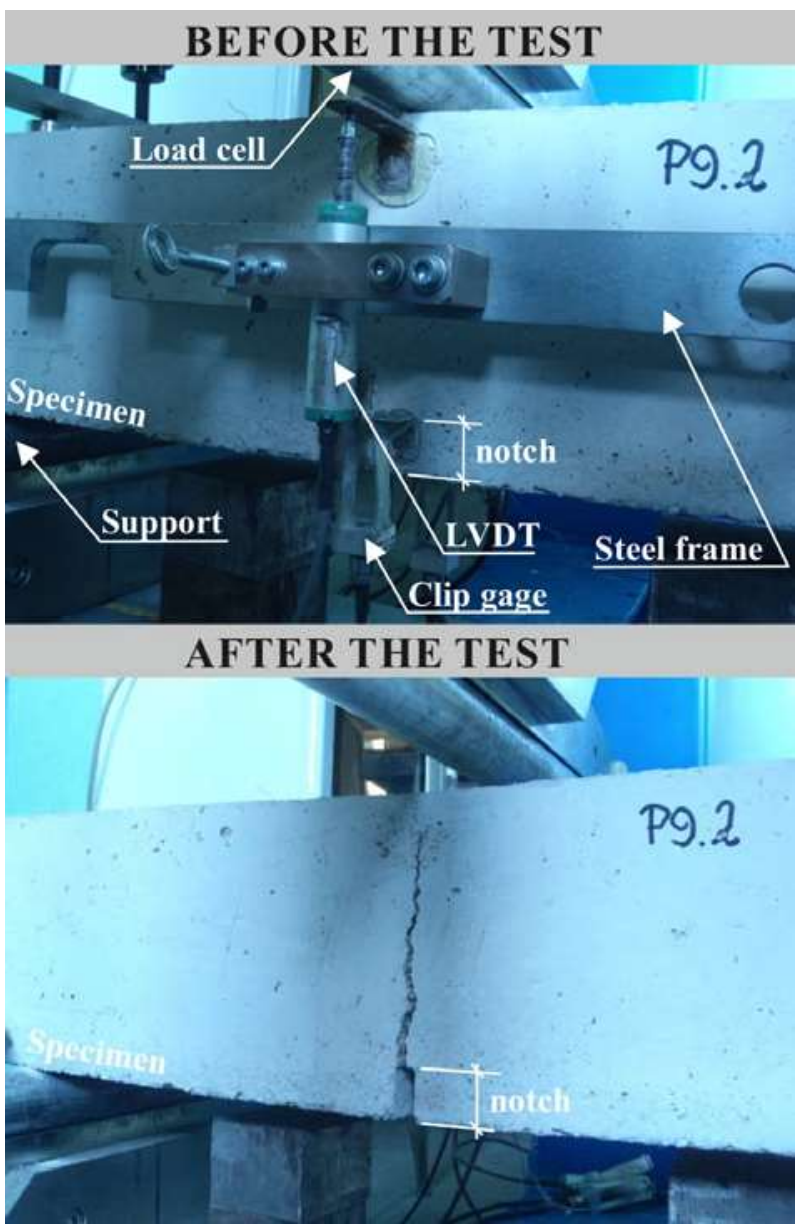

Fig. 3. View of the specimens at the test setup before and after the flexural test.

\section{Test results and discussion}

\subsection{Properties of RSFC in a fresh state}

The consistency of concrete mixes was determined using the slump test. The slump class consistency of a reference mix was $S 3$. The addition of fibers reduced the slump and the same workability of the concrete mix. The addition of fibers forms a network structure in concrete, which reduces the slump [7]. The results of the slump tests were presented in Table 3.

The recycled steel fibers did not have negative influence on the properties of the mix in a fresh state in case of all tested amounts. In the process of preparation of the concrete mix, uniform distribution of RSF in the concrete matrix was noted. Meanwhile, some researchers noted bundling of the RSF with the length of $50 \mathrm{~mm}$ at contents from the range of $15 \div 60 \mathrm{~kg} / \mathrm{m}^{3}$ [7]. The other researchers also noticed this problem, however, they indicated the reason of it. The type of mixer turned out to have a huge impact on the mixing process. The planetary mixer was the most suitable for that kind of fibers [15].

\subsection{Compressive strength}

Compressive strength of concrete matrix was equal to $51.5 \mathrm{MPa}$. The addition of fibers slightly influenced the compressive strength as well as the density of typical floor concrete. The average compressive strength of five specimens were presented in Table 3, where in parentheses the coefficients of variation were shown. The variation of $f_{c}$ of RSFC was in a range of $-1 \div 3 \%$ of the compressive strength of the plain matrix.

Industrial fibers in general have a minor influence on the compressive strength of the concrete matrix $[16,17,19]$. The fibers may slightly reduce or enhance the compressive strength of the matrix. Based on the results of investigation of RSFC presented in this paper and in other research available in the literature $[6,7,9,11,13,15]$ this conclusion was affirmed. In case of any FRC, the decrease or increases in the compressive strength of concrete may be even attributed to the natural scatters of the test results. However, some researchers observed a pronounced increase of compressive strength due to incorporation of RSF [14].

Table 3. The parameters of RSFC in a fresh and hardened state

\begin{tabular}{|c|c|c|c|}
\hline $\mathbf{V}_{\mathbf{f}}$ & $\begin{array}{c}\text { Density } \\
{\left[\mathbf{k g} / \mathbf{m}^{\mathbf{3}}\right]}\end{array}$ & $\begin{array}{c}\text { Slump } \\
{[\mathbf{m m}]}\end{array}$ & $\begin{array}{c}\text { Compressive } \\
\text { strength [MPa] }\end{array}$ \\
\hline $0 \%$ & 2.165 & 145 & $51.5(3)$ \\
\hline $0.38 \%$ & 2.141 & 140 & $51.0(2)$ \\
\hline $0.51 \%$ & 2.200 & 105 & $53.0(1)$ \\
\hline $0.76 \%$ & 2.197 & 90 & $51.2(1)$ \\
\hline
\end{tabular}

\subsection{Flexural parameters}

\subsubsection{Stress-CMOD curves}

The main results of flexural tests were depicted as stressCMOD curves. The results from five specimens and the 
average of them were presented for each mix in Fig. 4. The stress was determined from the load measured during the test using formula:

$$
\mathrm{f}_{\mathrm{i}}=\left(3 \mathrm{~F}_{\mathrm{i}} \mathrm{L}\right) /\left[2 \mathrm{~b}\left(\mathrm{~h}-\mathrm{h}_{\mathrm{sp}}\right)^{2}\right]
$$

where: $\mathrm{F}_{\mathrm{i}}$ - load recorded at $\mathrm{CMOD}_{\mathrm{i}}$; $\mathrm{L}$-span $(500 \mathrm{~mm})$; $\mathrm{b}, \mathrm{h}-$ width and high of the beam $(150 \mathrm{~mm}) ; \mathrm{h}_{\mathrm{sp}}-$ notch depth.

a)

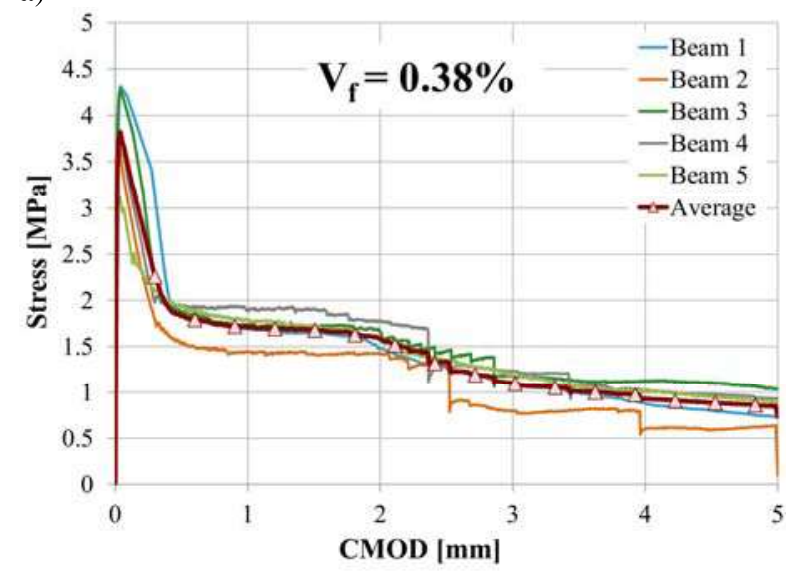

b)

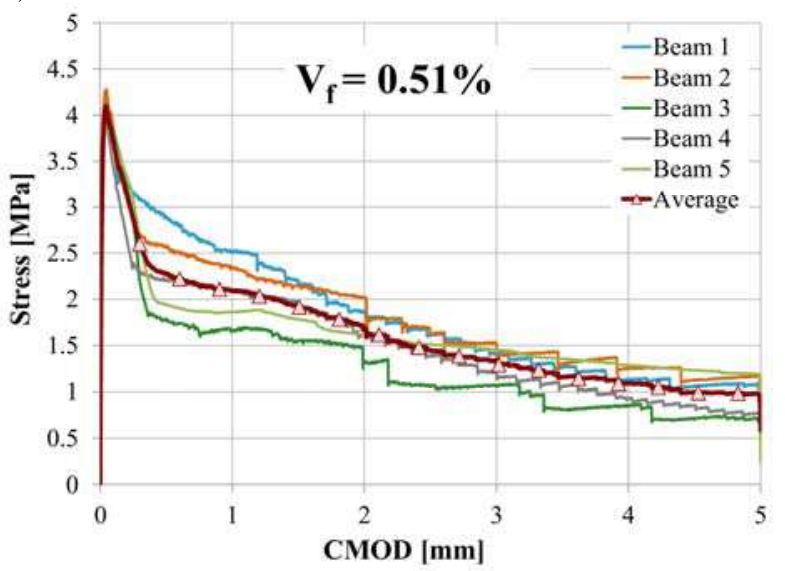

c)

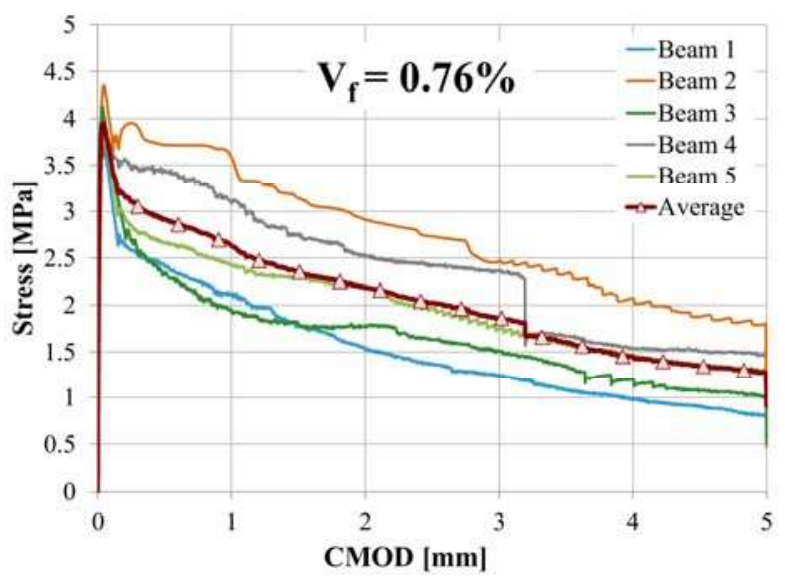

Fig. 4. Stress-CMOD curves of concrete reinforced with a dosage of RSF: (a) $\mathrm{V}_{\mathrm{f}}=0.38 \%$; (b) $\mathrm{V}_{\mathrm{f}}=0.51 \%$; (c) $\mathrm{V}_{\mathrm{f}}=$ $0.76 \%$.

The behavior of the plain concrete beams was almost linear-elastic up to the peak load. complete splitting into two parts was followed by slight descending branch. These results were not presented in Fig. 4.

From comparison of all the results presented in Fig. 4. it can be seen that with the increase of the fiber content the dispersion in the results increases. The results from five beams were the most comparable for the dosage of $30 \mathrm{~kg} / \mathrm{m}^{3}$ of fibers (Fig. 4a). While when the $60 \mathrm{~kg} / \mathrm{m}^{3}$ were applied much higher dispersion of the results was noted (Fig. 4c). It is worth to point out that no deterioration of the parameters of the mix in the fresh state during the mixing process was noted with the increase of the amount of the fibers.

In [13] the author compared the flexural behaviour of concrete presented in this paper and other one with the dosage of $30 \mathrm{~kg} / \mathrm{m}^{3}$ of RSF. In both cases the scatters of the results were negligible. The repeatability of the results from flexural tests where low amount of RSF fibers was applied was also noted in [15, 24].

The shape of the RSF was not regular (twisted, curved) and they had the tendency to be uniformly distributed in the concrete matrix. However, the dispersion of the results has appeared. The RSF were composed mainly of smaller fibers of variable length and a small amount of larger fibers. It can be seen in Fig. 1. The number of bigger fibers in the whole amount of fibers and their length were hard to define. For the mix with the highest dosage of RSF the amount of this fibers was certainly the biggest. Thus, a reasonable explanation of dispersion in the results is connected with the nonuniform distribution of bigger fibers in the concrete mix. It is obvious that when one of that kind of fibers appeared in the tensile zone in direction perpendicular to the crack the increase of flexural parameters was noted.

\subsubsection{Flexural tensile strengths}

The most pronounced effect of fibers was observed on the mechanical parameters of concrete in the postpeak phase due to bridging effect. Therefore, for RSFC it is crucial to determine the flexural parameters in this phase.

The flexural tensile strength at the limit of proportionality $\left(\mathrm{f}_{\mathrm{LOP}}\right)$, residual flexural tensile strengths $\left(f_{e q, i}\right)$ and equivalent flexural tensile strengths $\left(f_{R, i}\right)$ were derived from three-point flexural tests on notched beams. The parameters were determined based on the definition presented in RILEM TC 162-TDF [26]. The residual flexural tensile strengths $\left(\mathrm{f}_{\mathrm{R}, \mathrm{i}}\right)$ of RSFC were determined from the loads corresponding to CMOD equal to: $0.5 \mathrm{~mm}, 1.5 \mathrm{~mm}, 2.5 \mathrm{~mm}$ and $3.5 \mathrm{~mm}$ using equation (1). Please note that to evaluate all the flexural parameters the load-deflection curves were used and in the present paper the graphical presentation of the results contains stress-CMOD curves. All the flexural parameters were summarized in Table 4 . The aforementioned scatters in the results had their reflection in the coefficient of variation presented in the parentheses.

The proportional increase of the post-peak flexural parameters with the increase of the amount of fibers was observed. It can be clearly seen on the collation of the average stress-CMOD curves presented in Fig. 5. The 
values of residual flexural tensile strengths $\left(f_{R, i}\right)$ were matched with red in Fig. 5.

Incorporation of the RSF into concrete matrix slightly enhanced the $f_{\text {LOP }}$ and maximum tensile strength $\left(f_{p}\right)$. Analysing Fig. 4 and Fig. 5 it can be concluded that the inclusion of steel cord improved mainly the postpeak parameters of concrete matrix. The hardening phase was not affected by the fibers in the present study. It means that the RSF were actively working in the matrix only after the appearance of the main cracks. Only in this phase the fibers of the rarely observed slenderness were effective.

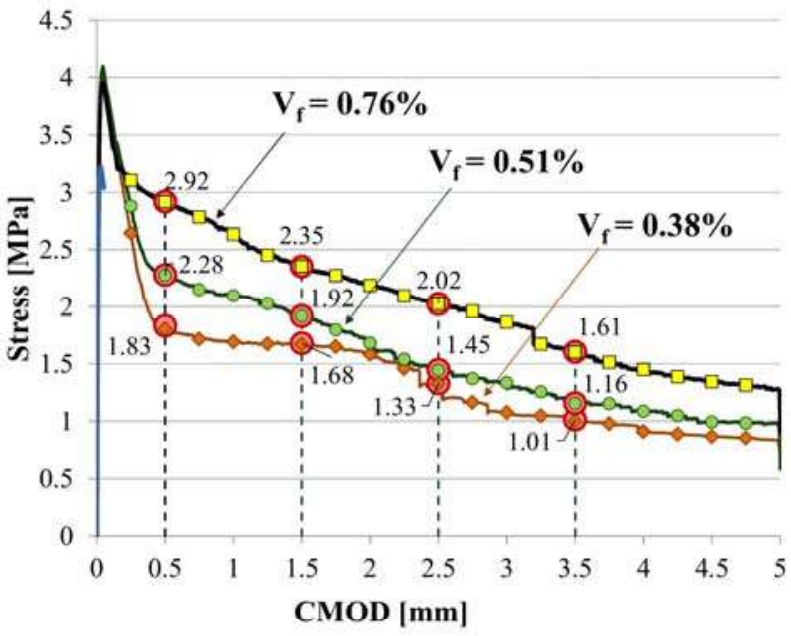

Fig. 5. Comparison of average stress-CMOD curves of RSFC.

Table 4. Flexural parameters of RSFC.

\begin{tabular}{|c|c|c|c|c|c|}
\hline \multicolumn{2}{|c|}{ Mix } & $0 \%$ & $0.38 \%$ & $0.51 \%$ & $0.76 \%$ \\
\hline \multicolumn{2}{|c|}{$\begin{array}{c}\text { Limit of proportionality } \\
\text { fLOP [MPa] }\end{array}$} & $\begin{array}{l}3.17 \\
(7)\end{array}$ & $\begin{array}{l}3.84 \\
(13)\end{array}$ & $\begin{array}{l}4.11 \\
(4)\end{array}$ & $\begin{array}{l}4.01 \\
(6)\end{array}$ \\
\hline \multicolumn{2}{|c|}{$\begin{array}{l}\text { Deflection at maximum } \\
\text { strength } \delta_{\mathrm{p}}(\mathrm{mm})\end{array}$} & $\begin{array}{l}0.04 \\
(23)\end{array}$ & $\begin{array}{l}0.04 \\
(41)\end{array}$ & $\begin{array}{l}0.04 \\
(37)\end{array}$ & $\begin{array}{l}0.04 \\
(35)\end{array}$ \\
\hline \multicolumn{2}{|c|}{$\begin{array}{l}\text { Maximum tensile } \\
\text { strength } \mathrm{f}_{\mathrm{p}}(\mathrm{MPa})\end{array}$} & $\begin{array}{c}3.23 \\
(7) \\
\end{array}$ & $\begin{array}{l}3.84 \\
(13) \\
\end{array}$ & $\begin{array}{l}4.11 \\
(4)\end{array}$ & $\begin{array}{l}4.01 \\
(6)\end{array}$ \\
\hline \multirow{2}{*}{$\begin{array}{c}\text { Equivalent } \\
\text { flexural } \\
\text { tensile } \\
\text { strength } \\
\text { [MPa] }\end{array}$} & $\mathrm{f}_{\text {eq2 }}$ & - & $\begin{array}{l}1.61 \\
(25)\end{array}$ & $\begin{array}{l}1.88 \\
(20)\end{array}$ & $\begin{array}{l}2.58 \\
(27)\end{array}$ \\
\hline & $\mathrm{f}_{\mathrm{eq} 3}$ & - & $\begin{array}{l}1.43 \\
(15)\end{array}$ & $\begin{array}{l}1.63 \\
(15)\end{array}$ & $\begin{array}{l}2.22 \\
(24)\end{array}$ \\
\hline \multirow{4}{*}{$\begin{array}{c}\text { Residual } \\
\text { flexural } \\
\text { tensile } \\
\text { strength } \\
\text { [MPa] }\end{array}$} & $\mathrm{f}_{\mathrm{R}, 1-\mathrm{CMOD}}$ & - & $\begin{array}{c}1.83 \\
(9)\end{array}$ & $\begin{array}{l}2.28 \\
(20)\end{array}$ & $\begin{array}{l}2.92 \\
(22)\end{array}$ \\
\hline & $\mathrm{f}_{\mathrm{R}, 2 \text {-CMOD }}$ & - & $\begin{array}{l}1.68 \\
(10)\end{array}$ & $\begin{array}{l}1.92 \\
(14)\end{array}$ & $\begin{array}{l}2.35 \\
(25)\end{array}$ \\
\hline & $\mathrm{f}_{\mathrm{R}, 3-\mathrm{CMOD}}$ & - & $\begin{array}{l}1.33 \\
(5)\end{array}$ & $\begin{array}{l}1.45 \\
(17)\end{array}$ & $\begin{array}{l}2.02 \\
(28)\end{array}$ \\
\hline & $\mathrm{f}_{\mathrm{R}, 4-\mathrm{CMOD}}$ & - & $\begin{array}{l}1.01 \\
(12)\end{array}$ & $\begin{array}{l}1.16 \\
(19)\end{array}$ & $\begin{array}{l}1.61 \\
(29)\end{array}$ \\
\hline \multicolumn{2}{|c|}{ Fracture energy $[\mathrm{kN} / \mathrm{m}]$} & - & $\begin{array}{c}14.87 \\
(12)\end{array}$ & $\begin{array}{c}17.06 \\
(13)\end{array}$ & $\begin{array}{c}22.36 \\
(22)\end{array}$ \\
\hline
\end{tabular}

\subsubsection{Application of RSF}

At this point the author would like to analyse the results obtained in laboratory experiments in terms of their application in structural calculations. The requirements set for fiber reinforced concrete mechanical parameters will be discussed.

The standard [27] recommends to declare the amount of fibers that would satisfy the minimum values of residual flexural tensile strengths achieved on the reference concrete. These values are $f_{R, 1}$ and $f_{R, 4}$ that should be equal to $1.5 \mathrm{MPa}$ and $1.0 \mathrm{MPa}$, respectively. Analysing Fig. 5 or Table 4 it can be seen that all tested amounts of fibers fulfil those requirements (even the dosage of $30 \mathrm{~kg} / \mathrm{m}^{3}$ ).

According to RILEM TC 162-TDF [28] the $\mathrm{f}_{\mathrm{R}, 1}$ and $f_{R, 4}$ are the values of residual flexural tensile stresses used in structural calculations of FRC. The $f_{R, 1}$ is used for Serviceability Limit States calculations, while for consideration of Ultimate Limit States the $\mathrm{f}_{R, 4}$ is applied. The variation of these strengths were presented in Fig. 6 . The linear relationship of $f_{R, i}$ from the amount of fibers can be noted. The equation to predict the values of strength were also proposed in the Fig. 6.

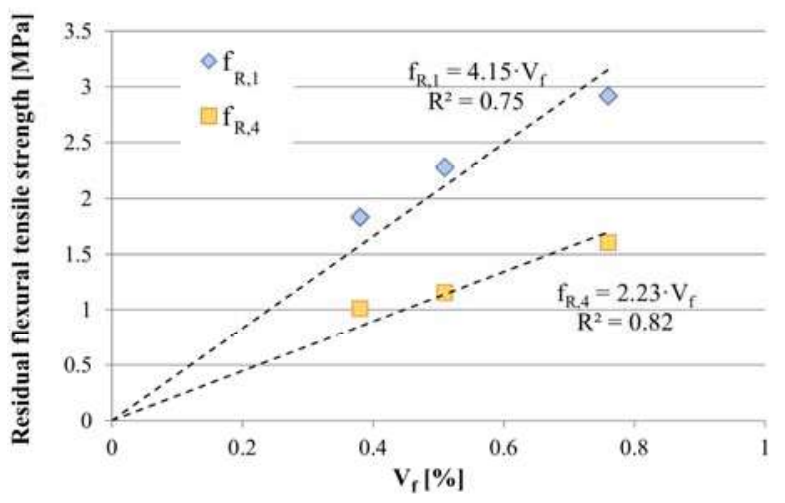

Fig. 6. Variation of residual flexural tensile strengths according to the amount of RSF.

The values of residual flexural tensile strengths obtained in experiments cannot be directly applied in calculation of structural elements made of RSFC. The values of $f_{R, 1}$ and $f_{R, 4}$ were calculated considering a linear elastic stress distribution in the section, see Fig. 7a. RILEM TC 162-TDF [28] suggests that in reality the tensile zone of the steel fiber reinforced concrete section is constant and reaches $66 \%$ of the high of the cross section for $\mathrm{CMOD}=0.5 \mathrm{~mm}$, as shown in Fig. $7 \mathrm{~b}$. Assuming the equality of bending moments in the cross section Fig. 7a and Fig. $7 \mathrm{~b}$ the stress $\sigma_{\mathrm{f} 1}$ can be calculated using formula (2):

$$
\sigma_{\mathrm{f} 1}=0.45 \cdot \mathrm{fR}_{\mathrm{R}, 1} \cdot \mathrm{kh}_{\mathrm{h}}
$$

The formula takes into account the size of the element by factor $\mathrm{k}_{\mathrm{h}}$ :

$$
\mathrm{k}_{\mathrm{h}}=1-0.6 \cdot[(\mathrm{h}-12.5) / 47.5]
$$

where: $\mathrm{h}$ - high of the element in $\mathrm{cm}$.

In case of ULS the tensile zone is assumed to be equal to $90 \%$ of the high of the cross section as shown in Fig. $7 \mathrm{c}$. The stress $\sigma_{\mathrm{f} 4} \mathrm{can}$ be derived analogically to the stress $\sigma_{\mathrm{fl}}$ using formula (4):

$$
\sigma_{\mathrm{f} 4}=0.37 \cdot \mathrm{f}_{\mathrm{R}, 4} \cdot \mathrm{kh}_{\mathrm{h}}
$$

The values of the stresses that can be taken into account in calculation of typical structural elements made of RSFC can be determined using the equation (2) and (4). 


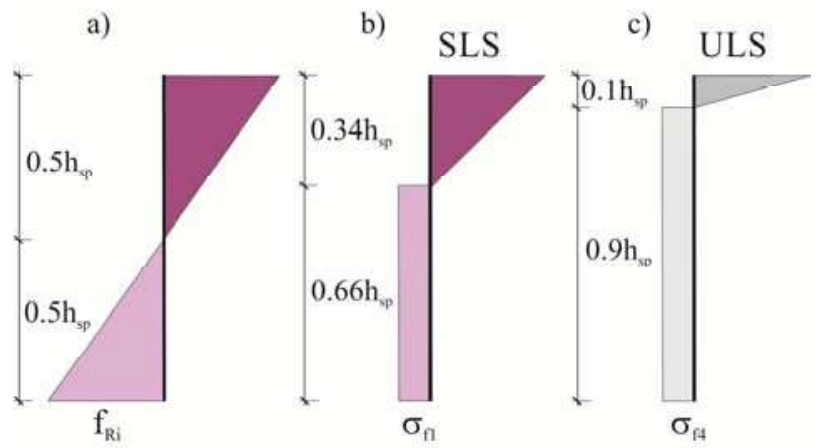

Fig. 7 a) Linear elastic stress distribution assumed in tests of FRC; Constant stress distribution in FRC assumed in calculation of: a) SLS; b) ULS.

\section{Conclusions}

The main objective of the present work was to provide more information about the influence of the fibers from the end-of-life tires on the mechanical parameters of the typical floor concrete. The investigated dosages of RSF were equal to $30 \mathrm{~kg} / \mathrm{m}^{3}, 40 \mathrm{~kg} / \mathrm{m}^{3}$ and $60 \mathrm{~kg} / \mathrm{m}^{3}$.

The investigations indicate that the fibers from the end-of-life tires could be applied as concrete reinforcement. Those amounts of RSF appeared to be enough to improve post-peak mechanical parameters of concrete. The residual strengths that could be directly used in structural calculations were presented.

Based on the experimental investigation some conclusions can be drawn:

- No obstacles were noted during the mixing process considering the untypical geometrical parameters of the fibers;

- The recycled steel fibers slightly affected the compressive strength of the concrete;

- The results of flexural tests were analysed based on the stress-CMOD curves. The scatter in the results of flexural tests were increasing with the increase of the amount of RSF. No accompanying deterioration of the parameters of the mix in the fresh state during the mixing process was noted. The smallest scatters in the results were noted in case of application of $30 \mathrm{~kg} / \mathrm{m}^{3}$, while the biggest in case of the samples containing $60 \mathrm{~kg} / \mathrm{m}^{3}$;

- The equivalent and residual flexural tensile strengths increased proportionally to the amount of the fibers. The maximum flexural tensile strength and flexural strength at the limit of proportionality was slightly improved by the fibers;

\section{Acknowledgement}

The author gratefully acknowledge the financial support provided by Ministry of Science and Higher Education (BK235/RB-6/2017).

\section{References}

1. D. Landi, S. Vitali, M. Germani, Procedia CIRP 48, 508-513 (2016)
2. V. Malijonyte, E. Dace, F. Romagnoli, I. Kliopova, M. Gedrovics, Energy Procedia 95, 257 - 264 (2016)

3. A. Depaolini, G. Bianchi, D. Fornai, A. Cardelli, M. Badalassi, C. Cardelli, E. Davoli, Chemosphere 184, 1320-1326 (2017)

4. M. Sol-Sánchez, F. Moreno-Navarro, M. C. RubioGámez, Construction and Building Materials 64, 150-156 (2014)

5. D. Landi, M. Marconia, I. Meoa, M. Germania, Procedia Manufacturing 21, 329-336 (2018)

6. M.A. Aiello, F. Leuzzi, G. Centonze, A. Maffezzoli, Waste Manage 29, 1960-1970 (2009)

7. O. Sengul, Constr Build Mater 122, 649-658 (2016)

8. H.A. Toutanji, Cement Concrete Comp 18, 135139 (1996)

9. G. Groli, A. P. Caldentey, F. Marchetto, F.A. Fernández, Eng Struct 101, 450-464 (2015)

10. H. Tlemat, K. Pilakoutas, K. Neocleous, Mater Struct 39, 365-377 (2006)

11. A. Caggiano, P. Folino, C. Lima, E. Martinelli, M. Pepe, Cement Concrete Comp 62, 146-155 (2015)

12. J. Domski, J. Katzer, M. Zakrzewski, T. Ponikiewski, J Clean Prod 158, 18-28 (2017)

13. M. Pająk, Architecture Civil Engineering Environment 11, 105-113 (2018)

14. M. Mastali, A. Dalvand, Constr Build Mater 125, 196-209 (2016)

15. G. Cenzone, M. Leone, M.A. Aiello, Constr Build Mater 36, 46-57 (2012)

16. A.M. Brandt, Compos Struct 86, 3-9 (2008)

17. A.A. Shah, Y. Ribakov, Materials and Design 32, 4122-4151 (2011)

18. H. Othman, H. Marzouk, Constr Build Mater 157, 899-908 (2017)

19. M.A. Glinicki, $X X V$ Ogólnopolskie warsztaty pracy projektanta konstrukcji (Szczyrk, 2010)

20. M. Pająk, T. Ponikiewski, Cem Wapno Beton 18, 335-342 (2013)

21. P. Rossi, P. Acker, Y. Mallier, Mater Struct 20, 436 9 (1987)

22. D.Y. Yoo, M.J. Kim, S.W. Kim, J.J. Park. Constr Build Mater 150, 383-394 (2017)

23. M. Pajak, T. Ponikiewski, Procedia Engineer 193, 218-225 (2017)

24. M. Pająk, Inżynieria i Budownictwo 5, 17-21 (2018)

25. PN-EN 12390-3 Testing hardened concrete - Part 3: Compressive strength of test specimens.

26. RILEM TC 162-TDF. Mater Struct 35, 579-82 (2002)

27. PN-EN 14889-1:2006 Fibres for concrete - Part 1: Steel fibres - Definitions, specifications and conformity.

28. RILEM TC 162-TDF. Mater Struct 36, 560-567 (2003) 